\title{
Ablation of the decorin gene enhances experimental hepatic fibrosis and impairs hepatic healing in mice
}

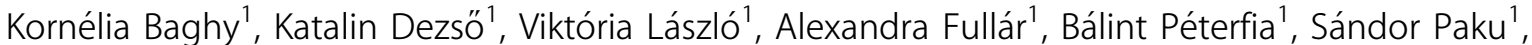 \\ Péter Nagy ${ }^{1}$, Zsuzsa Schaff ${ }^{2}$, Renato $\mathrm{V}$ lozzo $^{3}$ and Ilona Kovalszky ${ }^{1}$
}

Accumulation of connective tissue is a typical feature of chronic liver diseases. Decorin, a small leucine-rich proteoglycan, regulates collagen fibrillogenesis during development, and by directly blocking the bioactivity of transforming growth factor- $\beta 1$ (TGF $\beta 1$ ), it exerts a protective effect against fibrosis. However, no in vivo investigations on the role of decorin in liver have been performed before. In this study we used decorin-null (Dcn-/-) mice to establish the role of decorin in experimental liver fibrosis and repair. Not only the extent of experimentally induced liver fibrosis was more severe in Dcn-/- animals, but also the healing process was significantly delayed vis-ä-vis wild-type mice. Collagen I, III, and IV mRNA levels in Dcn-/- livers were higher than those of wild-type livers only in the first 2 months, but no difference was observed after 4 months of fibrosis induction, suggesting that the elevation of these proteins reflects a specific impairment of their degradation. Gelatinase assays confirmed this hypothesis as we found decreased MMP-2 and MMP-9 activity and higher expression of TIMP-1 and PAI-1 mRNA in Dcn-/- livers. In contrast, at the end of the recovery phase increased production rather than impaired degradation was found to be responsible for the excessive connective tissue deposition in livers of $D c n-/-$ mice. Higher expression of TGF $\beta 1$-inducible early responsive gene in decorin-null livers indicated enhanced bioactivity of TGF $\beta 1$ known to upregulate TIMP-1 and PAI-1 as well. Moreover, two main axes of TGF $\beta 1$-evoked signaling pathways were affected by decorin deficiency, namely the Erk1/2 and Smad3 were activated in Dcn-/- samples, whereas no significant difference in phospho-Smad2 was observed between mice with different genotypes. Collectively, our results indicate that the lack of decorin favors the development of hepatic fibrosis and attenuates its subsequent healing process at least in part by affecting the bioactivity of TGF $\beta 1$.

Laboratory Investigation (2011) 91, 439-451; doi:10.1038/labinvest.2010.172; published online 18 October 2010

KEYWORDS: decorin; Erk1/2; liver fibrosis; MMP-2; MMP-9; TGF $\beta 1$

Accumulation of connective tissue is a typical feature of several chronic diseases. ${ }^{1-3}$ The development of fibrosis is the result of imbalance between the synthesis and degradation of extracellular matrix proteins. ${ }^{4}$ Liver is especially prone to fibrotic remodeling ${ }^{5}$ because it is extremely susceptible to chronic and acute viral injury, toxic insults such as ethanol, and storage and autoimmune diseases. ${ }^{6-8}$ Without eradication of the etiological agent, liver fibrosis normally progresses to cirrhosis and destroys the normal architecture of the liver culminating with parenchymal and vascular decompensation of the organ. Furthermore, hepatic cirrhosis increases the probability of development of hepatocellular carcinoma. 9,10

In spite of recent progress, human liver cirrhosis is practically still incurable. ${ }^{1-13}$ Our better understanding of pro- and antifibrotic mechanisms failed to uncover curative approaches to combat this debilitating disease. Among factors implicated in the induction and maintenance of excess matrix production, transforming growth factor- $\beta 1$ (TGF $\beta 1$ ) occupies a central position. ${ }^{14-18}$ This peptide growth factor is capable of activating fibroblast and stellate cells, inhibiting their apoptosis and forcing them to synthesize excess amount of matrix proteins. ${ }^{17}$ This implies that inactivation of TGF $\beta 1$ could be a strategic approach in the management of liver fibrosis. $^{19}$

Decorin, a small leucine-rich proteoglycan (SLRP) $)^{20-22}$ can block the proliferation of cells that are dependent on TGF $\beta 1$ for their in vitro growth. ${ }^{23}$ This observation has been exploited in various in vivo models of experimental glomerulonephritis

\footnotetext{
${ }^{1}$ 1st Department of Pathology and Experimental Cancer Research, Semmelweis University, Budapest, Hungary; ${ }^{2}$ 2nd Department of Pathology and Experimental Cancer Research, Semmelweis University, Budapest, Hungary and ${ }^{3}$ Department of Pathology, Anatomy, and Cell Biology and The Cancer Cell Biology and Signaling Program, Kimmel Cancer Center, Thomas Jefferson University, Philadelphia, PA, USA

Correspondence: Dr I Kovalszky, MD, PhD, DSc, 1st Department of Pathology and Experimental Cancer Research, Semmelweis University, Ulloi ut 26, Budapest 1085, Hungary. E-mail: koval@korb1.sote.hu

Received 9 March 2010; revised 23 July 2010; accepted 18 August 2010
} 
and nephrosclerosis, as well as in scar formation models. ${ }^{24,25}$ However, there is no conclusive information on the role of decorin in the fibrotic remodeling of the liver. ${ }^{26}$ Decorin, as a regulator of matrix assembly targets not only TGF $\beta 1$, but it is involved in the maturation of collagen fibrils as well. ${ }^{27-29}$ Furthermore, it serves as ligand for growth factor receptors modulating signals initiated on EGFR, IGFR, and Met receptors. ${ }^{30-37}$ A central question is whether decorin-evoked modulation of signal transduction is directly implicated in fibrogenesis or is acting indirectly by controlling cell proliferation.

The main goal of this research was to determine whether decorin could have a protective role in liver fibrosis or whether the accumulation of this proteoglycan observed in human cirrhotic liver samples would be just due to a bystander effect. Furthermore, we wanted to determine whether the hypothesized role for decorin could be attributed to modulation of the TGF $\beta$ signaling pathway in the liver. In this study, we used an experimental animal model of liver fibrosis based on decorin-null and wild-type animals sharing the same genetic background. Our results provide evidence that decorin has a protective role in liver fibrogenesis insofar as the absence of decorin correlates with enhanced hepatic fibrosis and attenuation of its subsequent healing process.

\section{MATERIALS AND METHODS Decorin-Null Mice}

All animal experiments were performed under an institutionally approved protocol. Decorin-deficient mice were generated as previously described. ${ }^{29}$ In brief, the inactivation of the decorin gene was achieved by targeted disruption of the exon 2 inserting a PGK-Neo cassette. Two male and two female C57Bl/6 mice heterozygous for decorin gene $(D c n+/-)$, which were backcrossed into $\mathrm{C} 57 \mathrm{Bl} / 6$ background for nine generations, were bred until homozygosity. The genotype of the offspring was determined by PCR. Tail DNA was isolated by using high-salt method. Subsequently three primers were applied, sense and antisense specific for the exon 2, and one corresponding to the PGK-Neo cassette. PCR products were analyzed by $2 \%$ agarose gel electrophoresis.

\section{Thioacetamide Treatment}

For induction of hepatic fibrosis, we used 48 one-month-old male mice, all in a C57Bl/6 background. In all, 24 wild-type and $24 \mathrm{Dcn}-1-$ animals were exposed to thioacetamide (TA) dissolved in drinking water $(150 \mathrm{mg} / \mathrm{l})$. To obtain fully developed hepatic fibrosis, we subjected the animals to TA treatment for 4 months followed by an additional 4 months (recovery phase) in which the drug was withdrawn. Three animals were killed at each time point at monthly intervals. Age-matched untreated animals with identical genetic background served as controls. One half of the liver samples was frozen for further processing and the other half was fixed in $10 \%$ formaldehyde and embedded in paraffin for histological analysis. Paraffin sections were dewaxed in xylene and stained with hematoxylin and eosin or picrosirius red (PS), or processed further for immunohistochemistry. Stained sections were used for histological diagnosis and PS-stained sections were used for morphometric analysis.

\section{Cell Cultures, Decorin Gene Silencing, and TGF $\beta 1$ Treatment}

We used human hepatic stellate LX2 cells (a kind gift from Dr Scott Friedman) that were spontaneously immortalized by continuous growth in low serum. ${ }^{38}$ The cells were cultured in a humidified atmosphere containing $5 \% \mathrm{CO}_{2}$ at $37^{\circ} \mathrm{C}$ in Dulbecco's modified Eagle's medium (DMEM) supplemented with $10 \%$ fetal bovine serum (FBS), $100 \mathrm{U} / \mathrm{ml}$ penicillin and $100 \mu \mathrm{g} / \mathrm{ml}$ streptomycin (Sigma, St Louis, MO, USA). Routinely, $2 \times 10^{5}$ cells were seeded in six-well culture plates and transfected with Silencer Select Pre-Designed siRNA specific for decorin (siRNA ID: s223389; Applied Biosystems, Welterstadt, Germany) using SiPORT NeoFX Transfection Agent (Applied Biosystems) according to the manufacturer's instructions. Control cells were transfected with Silencer Select negative control siRNA (siRNA ID: 4390843). After $24 \mathrm{~h}$ the medium was replaced with DMEM supplemented with $0.2 \%$ FBS alone or in the presence of $2 \mathrm{ng} / \mathrm{ml}$ human recombinant TGF $\beta 1$ (cat. no. PHP143; AbD Serotec, Oxford, UK) for $48 \mathrm{~h}$.

\section{Morphometry, Fluorescence Immunostaining, and Quantitative Real-Time RT-PCR}

Picrosirius-red-stained sections were analyzed by using the Cue-2 program (Olympus, Japan). At least five fields were analyzed in each section. Frozen sections of the liver and cells grown on coverslips in a 24 -well plate $\left(4 \times 10^{4}\right.$ cells per well) were fixed in ice-cold methanol, washed in phosphate-buffered saline (PBS), blocked with 5 (w/v\%) BSA/PBS containing $10 \%$ non-immune serum of secondary antibody at $37^{\circ} \mathrm{C}$ for $30 \mathrm{~min}$. After washing, sections were incubated with the primary antibody diluted in PBS containing $1(\mathrm{w} / \mathrm{v} \%)$ BSA at $37^{\circ} \mathrm{C}$ for $1.5 \mathrm{~h}$ or at $4^{\circ} \mathrm{C}$ for $16 \mathrm{~h}$. Appropriate fluorescent secondary antibodies were applied at room temperature for $30 \mathrm{~min}$. Nuclei were stained with $4^{\prime}-6^{\prime}$-diamidino-phenylindole (DAPI). Primary and secondary antibodies with their appropriate dilutions are shown in Supplementary Table 1. Pictures were taken by Nikon Eclipse E600 microscope with the help of Lucia Cytogenetics version 1.5.6 program.

For RT-PCR, total RNAs were isolated from frozen livers and LX2 cells. After homogenization in liquid nitrogen TRIzol (Invitrogen, Carlsbad, CA, USA) method was used for RNA extraction. cDNAs were generated from $1 \mu \mathrm{g}$ total RNA by M-MLV Reverse Transcriptase kit (Invitrogen) following the instructions of the supplier. Real-time PCR was performed by ABI Prism 7000 Sequence Detection System (Applied Biosystems), using ABI TaqMan Gene Expression Assays for mouse: procollagen $\alpha 1$ (I) (assay ID: Mm00801666_g1), procollagen $\alpha 1$ (III) (assay ID: Mm00802331_m1), procollagen $\alpha 1$ (IV) (assay ID: Mm00802372_m1), TIMP-1 (assay ID: 
Mm00441818_m1), PAI-1 (assay ID: Mm00435860_m1), TIEG (TGF $\beta 1$-inducible early response gene; assay ID: Mm00449812_m1), TGF $\beta 1$ (assay ID: Mm01178819_m1) according to the manufacturer's protocol. Mouse $\beta$-actin was used as endogenous control (assay ID: Mm00607939_s1). For human procollagen $\alpha 1$ (I) (assay ID: Hs01076780_g1), decorin (assay ID: Hs00370383_m1) and $\alpha$-smooth muscle actin (assay ID: Hs00426835_g1), human GAPDH served as endogenous control (part no.: 4326317E). All samples were run in duplicates in $20 \mu \mathrm{l}$ with $50 \mathrm{ng}$ cDNA. Results were obtained as threshold cycle $\left(C_{\mathrm{T}}\right)$ values. Expression levels were calculated by using the $2^{-\Delta \Delta C_{\mathrm{T}}}$ method.

\section{Dot Blot, Western Blot and Zymography Assays}

Total proteins were extracted from frozen liver tissues. After homogenization in liquid nitrogen $1 \mathrm{ml}$ lysis buffer was added to the samples (20 mM TRIS ( $\mathrm{pH} 7.5$ ), $2 \mathrm{mM}$ EDTA, $150 \mathrm{mM} \mathrm{NaCl}, 1 \%$ Triton X-100, 0.5\% Protease Inhibitor Cocktail (Sigma), $2 \mathrm{mM} \mathrm{Na}_{3} \mathrm{VO}_{4}, 10 \mathrm{mM} \mathrm{NaF}$ ). Cultured cells were washed with PBS followed by addition $1 \mathrm{ml}$ of lysis buffer described above. Cells were scraped off with cell scraper and lysates were transferred into microcentrifuge tubes. After incubation for $30 \mathrm{~min}$ on ice, samples were centrifuged at $15000 \mathrm{~g}$ for $20 \mathrm{~min}$. Supernatants were kept and protein concentrations were measured as described before. $^{39}$

For dot blot, approximately $2 \mu \mathrm{g}$ of total protein was applied on PVDF membrane (Millipore, Billerica, MA, USA), endogenous peroxidase was blocked by incubating the membrane in $1 \% \mathrm{H}_{2} \mathrm{O}_{2}$ for $10 \mathrm{~min}$. Subsequently the membrane was blocked with $3(\mathrm{w} / \mathrm{v} \%)$ BSA in Tris-buffered saline (TBS). Primary antibody was applied at $4{ }^{\circ} \mathrm{C}$ for $16 \mathrm{~h}$. Appropriate HRP-conjugated secondary antibody was used for $45 \mathrm{~min}$, dots were detected by SuperSignal West Pico Chemiluminescent Substrate Kit (Pierce/Thermo Scientific, Waltham, MA, USA), and visualized by Kodak Image Station 4000MM Digital Imaging System. The density of the dots was also measured by the same system. A detailed list of the antibodies used in this study is presented in Supplementary Table 1.

For gelatinase (zymography) assays, proteins were isolated from frozen livers after homogenization in liquid nitrogen. The lysis buffer contained $50 \mathrm{mM}$ TRIS (pH 7.5), $500 \mathrm{mM}$ $\mathrm{NaCl}, 5 \mathrm{mM} \mathrm{CaCl}_{2}$. Protein aliquots $(15 \mu \mathrm{g})$ of each sample were analyzed on a $7.5 \%$ sodium dodecyl sulfate-polyacrylamide gel, containing $300 \mu \mathrm{g} / \mathrm{ml}$ gelatin. After electrophoresis at $200 \mathrm{~V}$ for $35 \mathrm{~min}$, the gel was washed in $2.5 \%$ Triton X-100 for $30 \mathrm{~min}$, then incubated for $18 \mathrm{~h}$ at $37^{\circ} \mathrm{C}$ in a solution containing $50 \mathrm{mM}$ Tris (pH 7.5), and $10 \mathrm{mM} \mathrm{CaCl}_{2}$. Gels were fixed in 30\% methanol/10\% acetic acid for $30 \mathrm{~min}$, then stained with Coomassie brilliant blue for another $30 \mathrm{~min}$. Areas of gelatinase activity appeared as transparent bands on the blue background. The intensity of the bands was determined by densitometry using a Kodak IS4000MM Digital Imaging System.
For western blotting, proteins were isolated as for dot blot, $30 \mu \mathrm{g}$ of total proteins was mixed with loading buffer containing $\beta$-mercaptoethanol and was incubated at $95^{\circ} \mathrm{C}$ for $5 \mathrm{~min}$. Denatured samples were loaded onto a $10 \%$ polyacrylamide gel and were run for $30 \mathrm{~min}$ at $200 \mathrm{~V}$ on a Mini Protean vertical electrophoresis equipment (Bio-Rad, Hercules, CA, USA). Proteins were transferred to PVDF membrane (Millipore) by blotting for $1.5 \mathrm{~h}$ at $100 \mathrm{~V}$. Ponceau staining was applied to determine blotting efficiency. Membranes were blocked with 3 (w/v\%) non-fat dry milk (Bio-Rad) in TBS for $1 \mathrm{~h}$ followed by incubation with the primary antibodies at $4{ }^{\circ} \mathrm{C}$ for $16 \mathrm{~h}$. Mouse $\beta$-actin or human GAPDH served as loading control. Membranes were washed five times with TBS containing $0.5(\mathrm{v} / \mathrm{v} \%)$ Tween 20 , then were incubated with appropriate HRP-conjugated secondary antibodies for $1 \mathrm{~h}$.

\section{Hydroxyproline Determination}

Liver samples were homogenized with 10 volumes of physiological salt solution and precipitated with $1 \mathrm{ml}$ of 10 (v/v\%) trichloroacetic acid. Pellets were washed with ethanol/ diethyl ether in a ratio of 3:1, dried under vacuum and transferred to glass cuvettes. Hydrolysis was performed in $6 \mathrm{~N}$ $\mathrm{HCl}$ followed by incubation at $120^{\circ} \mathrm{C}$ for $16 \mathrm{~h}$. Hydroxyproline determination was performed as described before. ${ }^{40,41}$ In brief, $\mathrm{pH}$ of hydrolysates was adjusted to $6-7$ by adding $5 \mathrm{~N}$ $\mathrm{NaOH}$ in a final volume of $12 \mathrm{ml}$. Aliquots $(2 \mathrm{ml})$ of the samples were transferred into clean tubes and $1-1 \mathrm{ml}$ of $50 \mathrm{mM}$ chloramine $\mathrm{T}$ (dissolved in citrate acetate buffer, $\mathrm{pH}$ 6 ) in the presence of $30 \%$ of methoxyethanol was added. After $20 \mathrm{~min}$ incubation at room temperature the reaction was stopped with $3.15 \mathrm{~N}$ perchloric acid followed by of $20 \%$ p-dimethylaminobenzaldehyde dissolved in methoxyethanol. The color was developed by incubation for $20 \mathrm{~min}$ at $60^{\circ} \mathrm{C}$. After cooling, the absorbance was measured at $557 \mathrm{~nm}$. Hydroxyproline content was calculated from standard curves generated with pure hydroxyproline solutions of known concentrations.

\section{Statistical Analysis}

All the data were graphed and analyzed using the SigmaPlot and SigmaStat software packages (SPSS, version 11.0). Statistical analysis among groups was assessed using twotailed Student's $t$-test after data normalization by logarithmic transformation $(\log 10)$. Normal distribution was further proved by $\mathrm{F}$ test. The values were considered statistically significant with $P<0.05$.

\section{RESULTS \\ Hepatic Fibrosis Is Accentuated and Healing Is Protracted in Decorin-Null Mice}

Picrosirius red staining for connective tissue clearly showed that Dcn-/- mice accumulated more connective tissue in their livers as compared to the wild-type mice in response to chronic liver injury (Figure 1a). The fibrotic tissue localized 
a

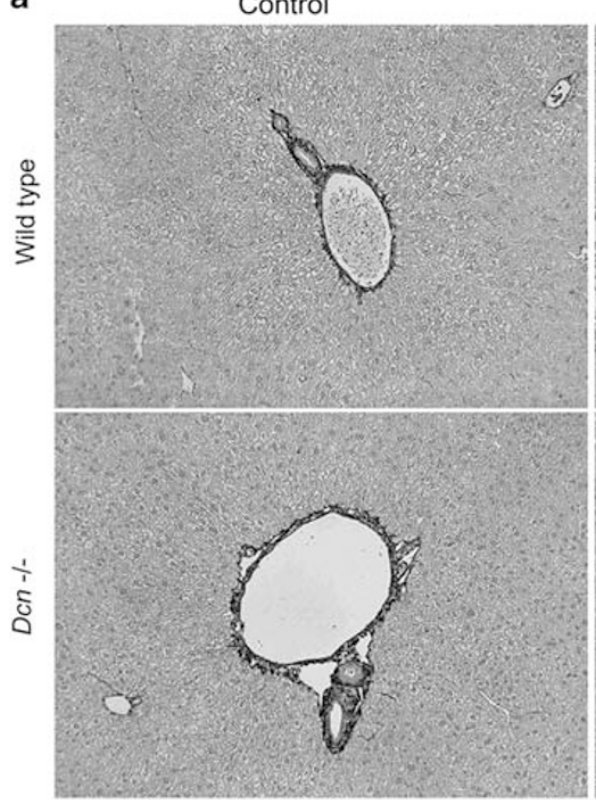

b

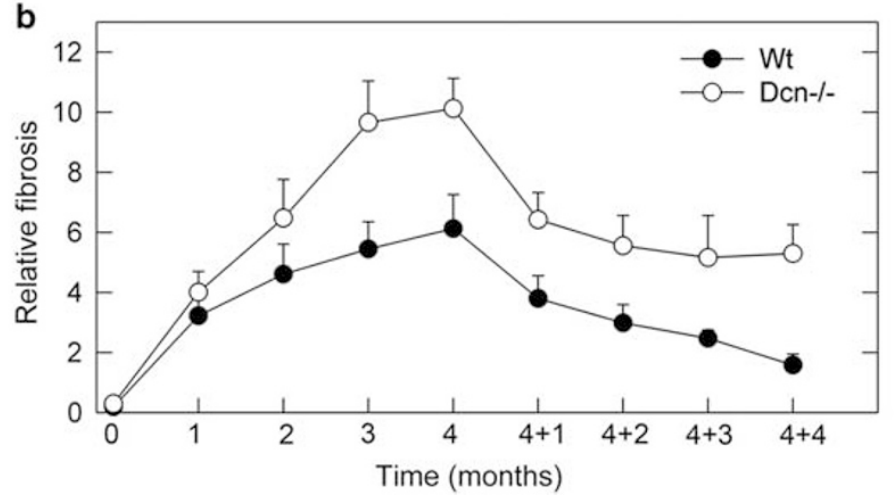

TA4

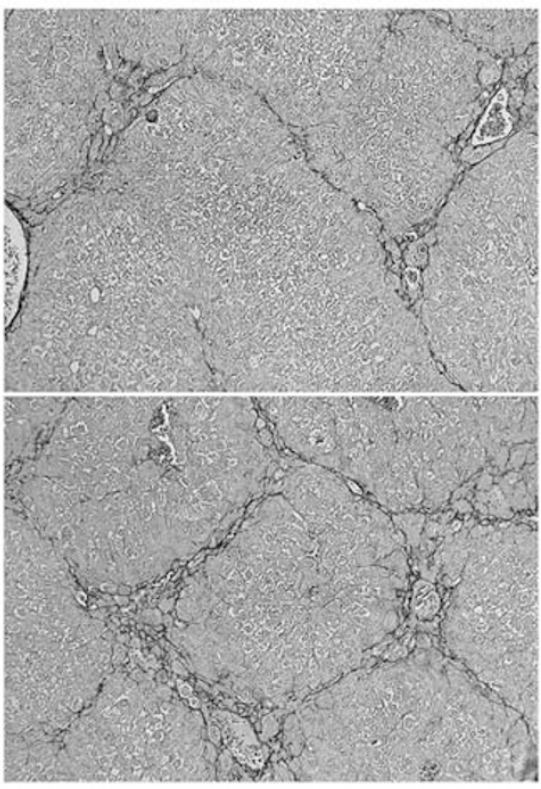

$\mathrm{TA} 4+4$

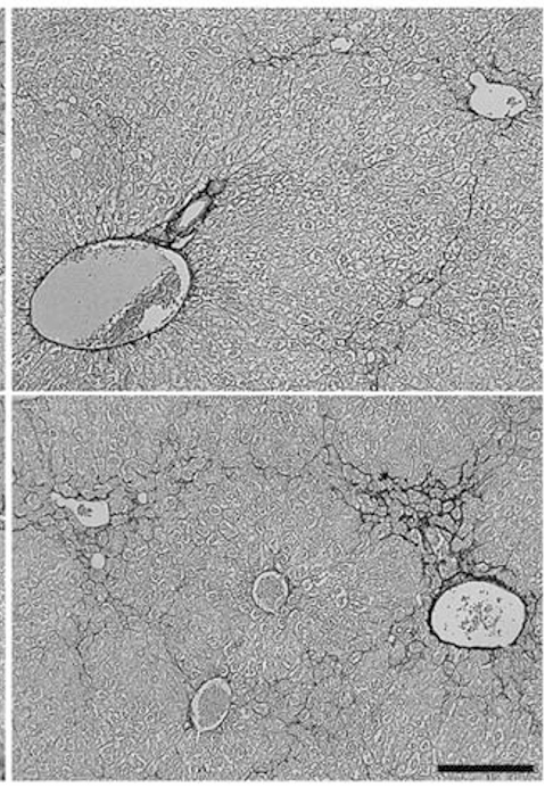

C

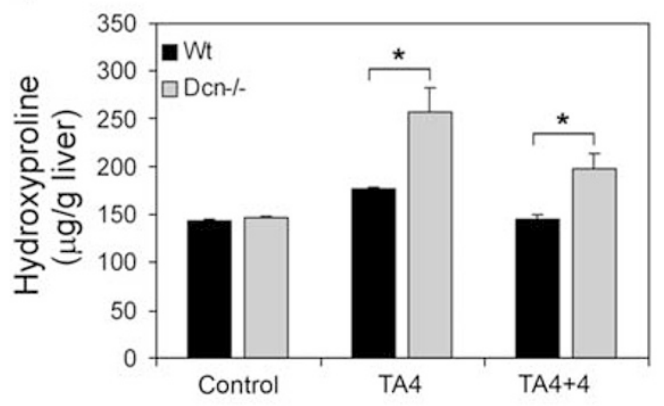

Figure 1 Hepatic fibrosis is accentuated and healing is delayed in Dcn-/- mice. (a) Picrosirius-stained sections from the liver of wild-type and Dcn-/- mice without treatment (first column), after 4 months of thioacetamide treatment (second column), and 4 months after the withdrawal of the thioacetamide (third column). Scale bar $=150 \mu \mathrm{m}$. (b) Quantification of hepatic fibrosis by morphometric analysis of livers from wild-type and Dcn-/animals as indicated. Values represent the mean (\%) \pm s.e.m. of three animals. All the values from 2 to $4+4$ months have $P<0.01$. (c) Quantification of hydroxyproline in whole liver extracts of wild-type and decorin-null livers. Values represent the mean (\%) \pm s.e.m. of $n=3 ;{ }^{\star} P<0.05$.

mainly to the acino-peripheral regions but its deposition in the sinusoids could also be observed. In Dcn-/- livers, following a 4-month exposure to TA, formation of pseudolobules, typically observed in early cirrhosis, could be detected in contrast to the wild-type mice (Figure 1a). Four months after the cessation of TA treatment, the majority of connective tissue fibrils positive for PS were resolved in the liver of wild-type animals. In contrast, $D c n-/-$ livers still contained considerable amounts of fibrous tissue (Figure 1a). Morphometric analysis of picrosirius-positive tissue confirmed our visual observations (Figure $1 \mathrm{~b}$ ). The intensity of picrosirius staining was higher already in the liver of untreated $D c n-/-$ mice. At each time point throughout fibrogenesis and regression higher amounts of connective tissue were detected in mice lacking decorin (Figure $1 \mathrm{~b}$ ), and these differences were statistically significant $(P<0.05)$.
Hydroxyproline determination provided further confirmation for the elevated amount of collagens (Figure 1c). In the liver of wild-type mice the production of fibrous tissue stopped after 4 month of TA exposure and no additional connective tissue deposition was observed thereafter. In contrast, in Dcn-/- mice extracellular matrix deposition progressed until the end of the experimental period (8 months). Comparable patterns were observed for changes in hydroxyproline content (Figure 1c).

Next, we immunostained the livers of the various groups using antibodies against collagen type I, a major indicator of hepatic fibrosis, and against decorin protein core (Figure 2a). The results showed a significant deposition of collagen type I in the decorin-null mice both at the end of the experimental liver injury and after 4 months of recovery with TA-free water (Figure 2a). Similar results were obtained with antibodies 

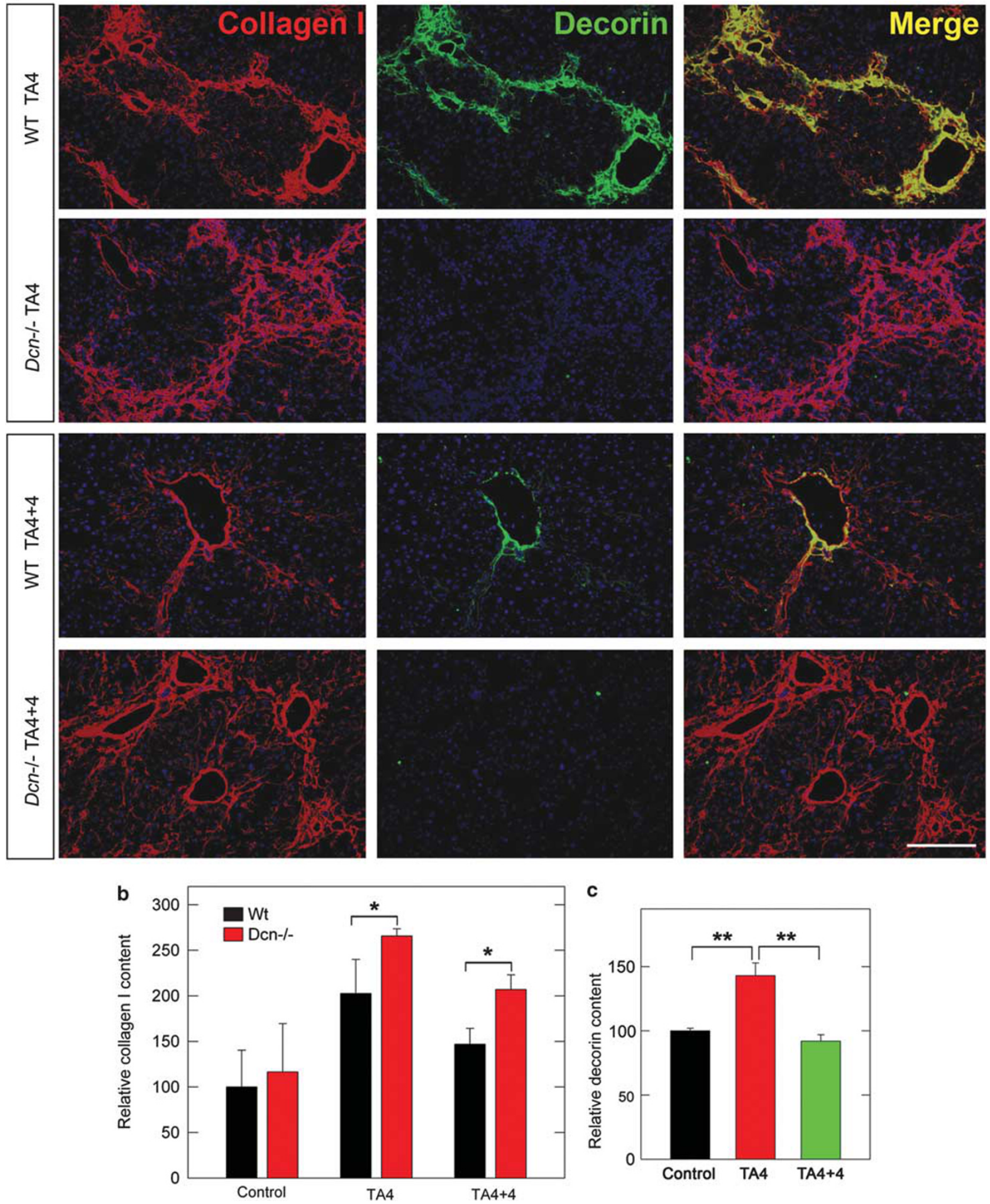

Figure 2 Changes in collagen type I and decorin in hepatic fibrosis and its healing in Dcn-/- mice. (a) Double immunostaining for collagen I and decorin in representative liver samples from all the various experimentally treated animals as indicated. Collagen is shown as red, decorin as green, nuclei are stained with DAPI. Representative Wt and Dcn-/- controls are shown in Supplementary Figure S2. Scale bar $=200 \mu \mathrm{m}$. (b) Quantification of collagen I content in livers from wild-type and decorin-null mice. Results are expressed as mean intensity of dots after densitometry. Wild-type non-treated control was considered as $100 \%$. Values represent the mean \pm s.d. of three animals $\left({ }^{*}<<0.05\right)$. (c) Quantification of decorin levels by immunoblotting of total liver lysates from wild-type untreated mice, and from mice treated for 4 months with TA or for an additional 4 months in TA-free conditions ( $* \star P<0.01$ ). 
against collagen types III and IV (Supplementary Figure S1). Quantification of collagen type I showed an increase after 4 months of TA exposure that was statistically significant $(P<0.05)$; the enhanced deposition of collagen $\mathrm{I}$ in the $D c n-/-$ livers was also statistically significant at the end of the regression period $(P<0.05$; Figure $2 b)$.

\section{Fibrotic Remodeling Enhances Decorin Levels in Wild-Type Livers}

By immunostaining, as expected, decorin was detectable only in wild-type animals where it was deposited in periportal connective tissue and around the central veins (Supplementary Figure S2). Notably, during fibrogenesis decorin levels increased in the wild-type animals and accumulated along fibrotic septa (Figure 2a). By quantitative immunoblotting, a significant increase $(P<0.01)$ in the amount of decorin was detected in lysates of fibrotic livers vis-à-vis the untreated control samples (Figure 2c). After 4 months of regression, a statistically relevant $(P<0.01)$ decrease was observed in wildtype mice (Figure 2c). The amount of decorin in control livers and in those taken at the end point of regression was practically identical $(P=0.2)$.

\section{Elevation of Collagens I, III, and IV mRNA Levels in the Liver of Dcn-I-Animals following Hepatic Injury}

Next, we determined the mRNA levels of collagens type I, III, and IV using quantitative RT-PCR analysis. These mRNA levels were determined in each liver sample at each time point. Notably, we found no statistically significant changes in mRNA levels of any collagens tested after 4 months of liver injury. However, at the end of the regression period $(\mathrm{TA} 4+4)$ the steady-state levels of all the three types of collagens were significantly elevated in $D c n-/-$ animals vis-à-vis wild-type mice $(P<0.05$; Figure $3 \mathrm{a}-\mathrm{c})$.

\section{Activity of MMP-2 and MMP-9 and Expression of Their Inhibitors TIMP-1 and PAI-1}

Gelatinase activity of liver homogenates was determined by using zymography (Figure 4a). Quantification of the zymography data revealed no difference in either matrix metalloprotease (MMP)-2 or in MMP-9 activity in the control samples between wild-type and decorin-null mice (Figure $4 \mathrm{~b}$ and c). In contrast, in the wild-type fibrotic livers, activity of both MMP-2 and MMP-9 significantly increased $(P<0.01)$ and to a greater extent than that of decorin-null animals $(P<0.01)$. These changes regressed by the end of the recovery period showing only subtle differences between the two genotypes (Figure $4 \mathrm{~b}$ and $\mathrm{c}$ ).

Fibrogenesis in Dcn-/- livers was characterized not only by low activity of MMP- 2 and MMP-9 but also by enhanced expressions of TIMP-1 and PAI-1, two well-known MMP inhibitors, especially at the end of the recovery period (Figure 5).

Collectively, these results suggest that decorin is directly involved in regulating the fine balance of synthesis and degradation during hepatic fibrosis and healing.

\section{Lack of Decorin in Experimental Hepatic Fibrosis Enhances the Expression of TGF $\beta 1$ and TGF $\beta$ 1-Inducible Early Response Gene}

To establish whether TGF $\beta 1$ would exert a stronger effect in animals lacking functional decorin, we determined the expression of TGF $\beta 1$ and TIEG as a marker for the efficacy and activity of the growth factor. Quantitative RT-PCR revealed approximately sixfold increase in TIEG mRNA level in Dcn-/liver samples $(P<0.01)$ compared with wild-type during both fibrogenesis and regression (Figure 6a), whereas TGF $\beta 1$ mRNA levels increased by threefold even in the Dcn-/control group $(P<0.05$; Figure $6 \mathrm{~b})$. After 4 months of TA treatment, there was a 20 -fold increase of TGF $\beta 1$ in Dcn-/samples in contrast to only a threefold increase in wild-type $(P<0.01$; Figure $6 \mathrm{~b})$. After the regression period, TGF $\beta 1$ expression decreased to barely detectable levels, even lower than the wild-type controls (Figure 6b). Thus, the absence of decorin potentiates TGF $\beta 1$ bioactivity during hepatic fibrosis and therapeutic approaches to enhance decorin expression in the liver could represent a novel mechanism to counteract this important fibrogenic factor.
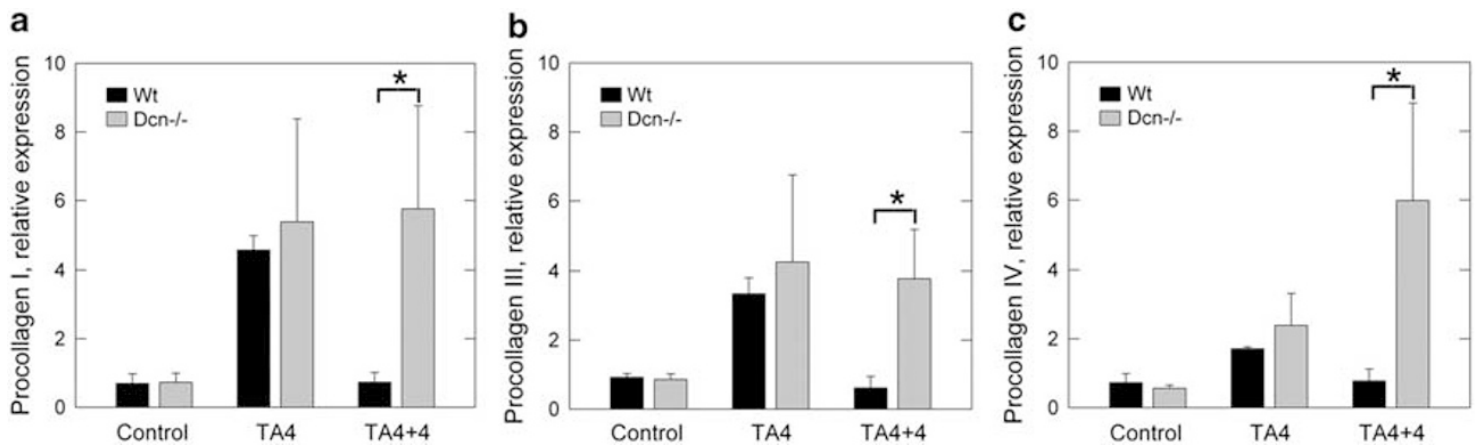

Figure 3 Elevation of collagen I, III, and IV mRNA levels in the liver of Dcn-/- animals following hepatic injury. (a-c) Quantification of mRNA levels for procollagens type I, III and IV as determined by quantitative RT-PCR analysis. The data represent mean $\pm \mathrm{s}$.d. of $n=3$; ${ }^{\star} P<0.05$. Levels are expressed in folds, normalized to endogenous $\beta$-actin amplified in parallel. 

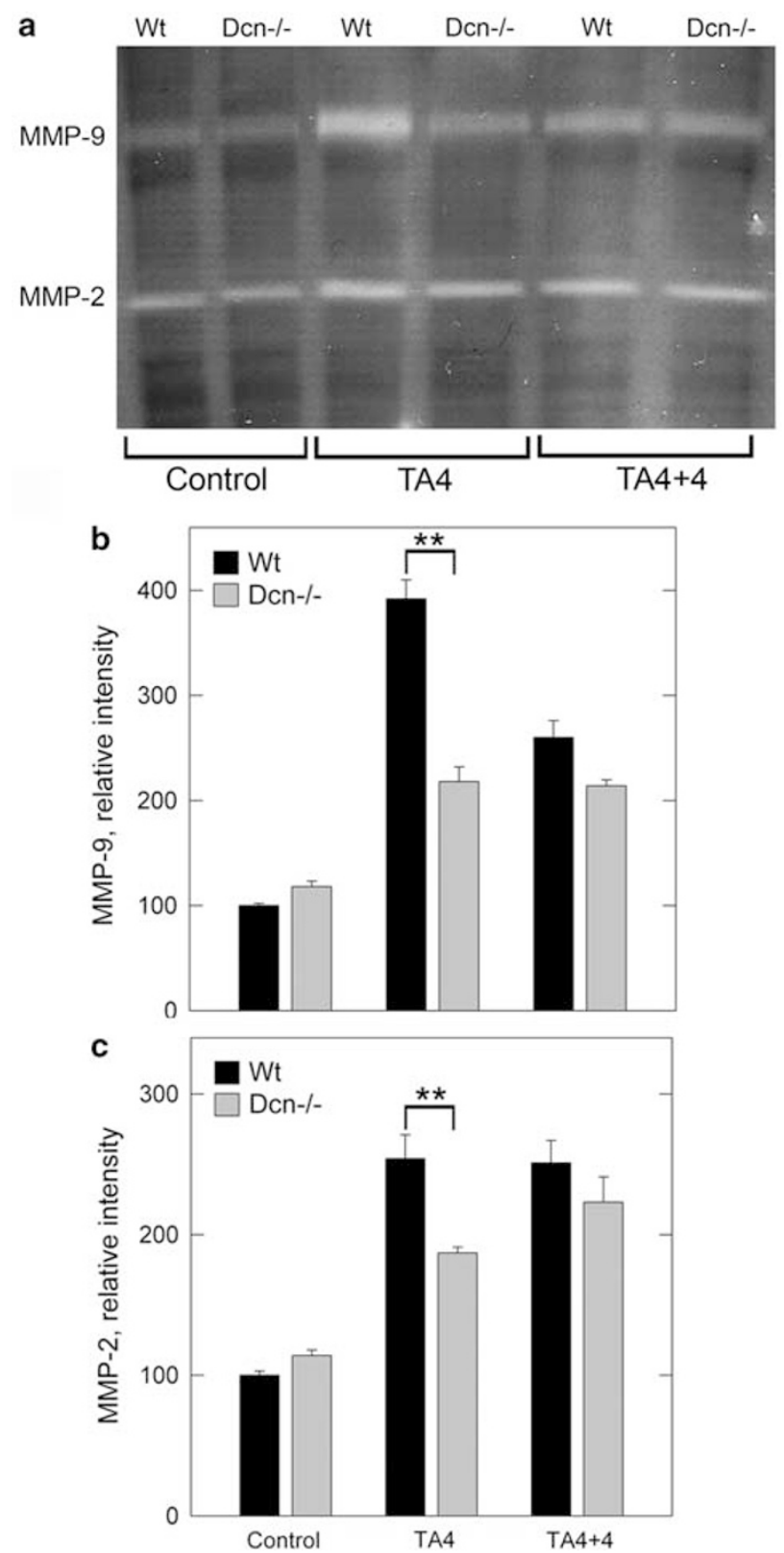

Figure 4 MMP elevation during hepatic fibrosis. (a) Zymogram using liver homogenates of wild-type and Dcn-/- mice without treatment (control), at 4 months of thioacetamide treatment (TA4), and at 4 months after the withdrawal of the chemical (TA4 +4). (b, c) Quantification of zymograms as those shown in a using scanning densitometry. The values represent the mean intensity $(\%) \pm$ s.d. of two experiments run in triplicate; ${ }^{* * P}<0.01$.

\section{Increased $\alpha$-Smooth Muscle Actin and Enhanced Phosphorylation of Erk1/2 and Smad3 in Decorin-Null Animals}

To investigate what molecular pathways could be operational in our experimental animal model, we determined by immunoblotting the amounts of Erk1/2 and their phosphorylated forms (P-Erk1/2), as well as phospho-Smad2 (P-Smad2) and phospho-Smad3 (P-Smad3), all known downstream effectors of the TGF $\beta 1$ signaling pathways. In
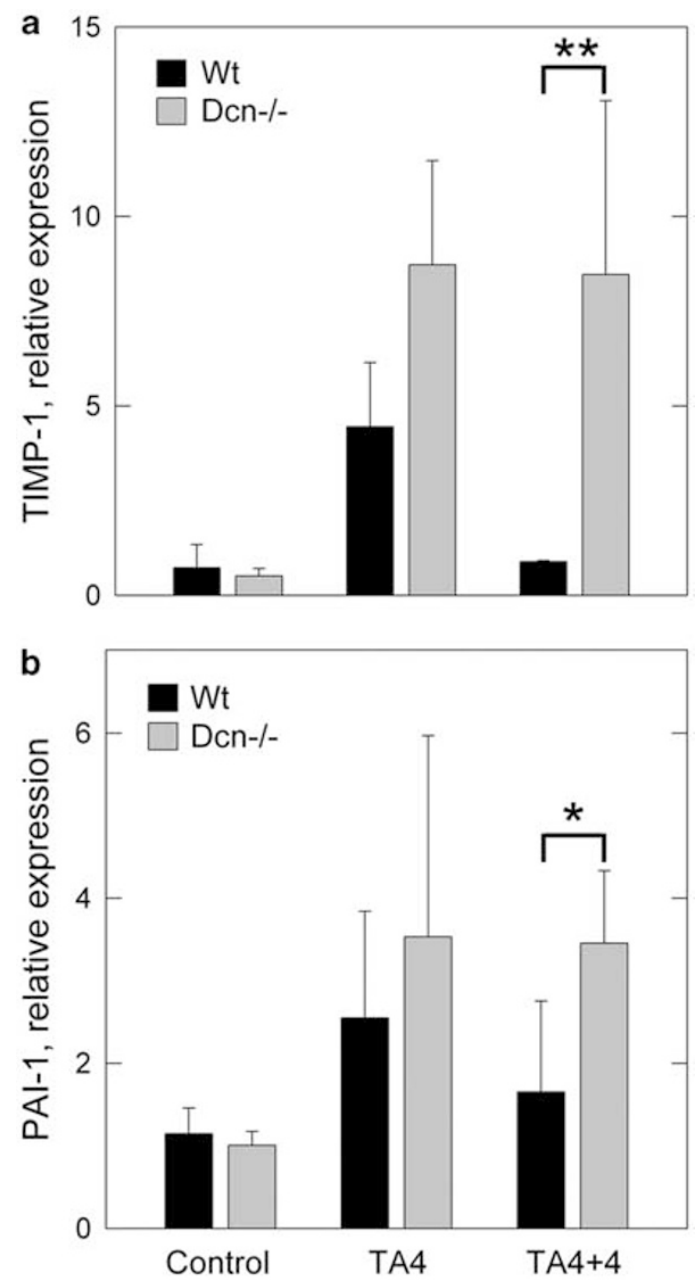

Figure 5 Elevation of TIMP-1 and PAI-1 mRNA levels in Dcn-/- liver following experimental hepatic fibrosis. (a, b) RT-PCR analysis of TIMP-1 andPAI-1 mRNA in whole liver of wild-type and decorin-null animals as indicated. The designations are the same as those in Figure 1. The data represent mean \pm s.d. of $n=3 ;{ }^{*} P<0.01$ and ${ }^{\star} P<0.05$. The relative expression levels were calculated by using $2^{-\Delta \Delta C_{\mathrm{T}}}$ method, using $\beta$-actin as endogenous control.

addition, we determined the levels of $\alpha$-smooth muscle actin, a known marker of fibrogenic cells such as the hepatic stellate cells (Figure 7). In fibrotic livers (TA4), regardless of their genetic background, the amounts of Erk1/2 and P-Smad2 significantly $(P<0.05)$ increased, as determined by scanning densitometry of several immunoblottings (Supplementary Figure S3). However, at the end of regression period, the amounts of these proteins did not statistically differ from controls. Concurrently, the levels of $\alpha$-smooth muscle actin were significantly elevated after 4 months of treatment $(P<0.01)$ and after the recovery period in the decorin-null animals compared with wild type $(P<0.01$; Figure $7 \mathrm{a}$ and $\mathrm{b})$.

In $D c n-/-$ samples a slight increase was observed in case of Erk1/2 and P-Smad2 compared with wild type. However, although Erk1/2 were not phosphorylated in the wild-type fibrotic liver, the level of phosphorylation increased to $183 \%$ 
in decorin-null samples $(P<0.05$; Figure $7 \mathrm{~b})$. At the end point of the recovery phase, lower amounts of active Erk1/2 were detected vis-à-vis untreated samples, and $D c n-/-$
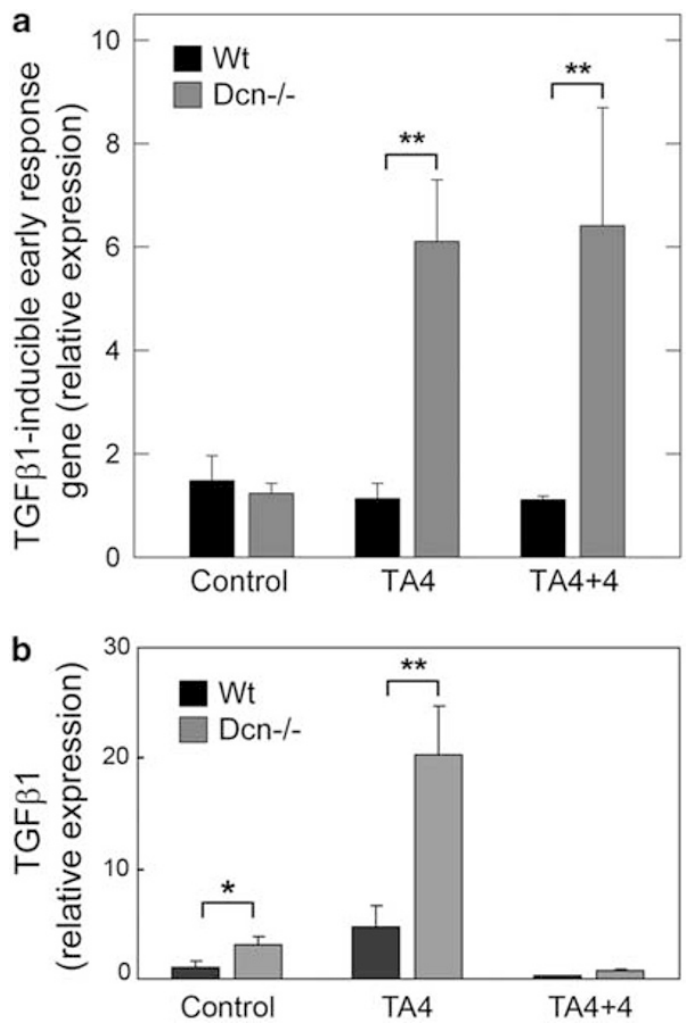

Figure 6 Genetic ablation of decorin gene enhances the expression of the TGF $\beta 1$-inducible early responsive gene (TIEG) and TGF $\beta 1$ in experimental hepatic fibrosis. Real-time PCR analysis of (a) TGF $\beta 1$-inducible early response gene (TIEG) and (b) TGF $\beta 1$ expression in whole-liver extracts. The designations are the same as those in Figure 1. The data represent mean \pm s.d. of three experiments run in triplicate and are presented as expression relative to endogenous $\beta$-actin levels; ${ }^{*} P<0.05$, ${ }^{*} P<0.01$. samples contained significantly higher amounts of Erk $1 / 2$ as compared with wild type $(P<0.05)$. The level of phosphoSmad3 protein increased during fibrogenesis showing a 2.3 -fold increase in wild-type and 8.37 -fold increase in decorin-null livers after 4 month of TA treatment $(P<0.01)$. At the end of the recovery period $(\mathrm{TA} 4+4)$ similar amounts of P-Smad3 were detected as in control samples (Figure 7b).

These results suggest that the lack of decorin leads to enhanced accumulation of $\alpha$-smooth muscle actin-positive cells, and to increased phosphorylation of Erk1/2 and Smad3 proteins without significantly affecting the levels of P-Smad2.

\section{Lack or Reduced Decorin Content Results in Enhanced Activation of Hepatic Stellate Cells}

To determine whether hepatic stellate cells, known as the main fibrogenic cell type in the liver, could be involved in the action of decorin, we investigated the effects of TGF $\beta 1$ in the presence or absence of endogenous decorin. To this end, we used human hepatic stellate LX2 cells, which were spontaneously immortalized by continuous growth in low serum. ${ }^{38}$ These cells express $\alpha$-smooth muscle actin, vimentin, glial fibrillary acid protein and show a retinoid phenotype typical of stellate cells. Decorin was silenced by specific siRNA, whereas control cells were transfected with scrambled siRNA. The siRNA-mediated silencing reduced the decorin mRNA level to $\sim 38 \%$ (not shown). After TGF $\beta 1$ exposure for $48 \mathrm{~h}$, cells with downregulated decorin content showed a 4.42 -fold increase in procollagen $\alpha 1(\mathrm{I})$ steady-state mRNA levels in contrast to cells transfected with scrambled siRNA that exhibited a 2.78 -fold increase $(P<0.01$; Figure 8 a). Similar results were obtained with $\alpha$-smooth muscle actin, insofar as treatment with the growth factor caused a 1.34 -fold increase in mRNA level of cells with normal decorin content, whereas 2.32-fold increase was detected in decorin knockdown samples $(P<0.01$; Figure $8 \mathrm{a})$.
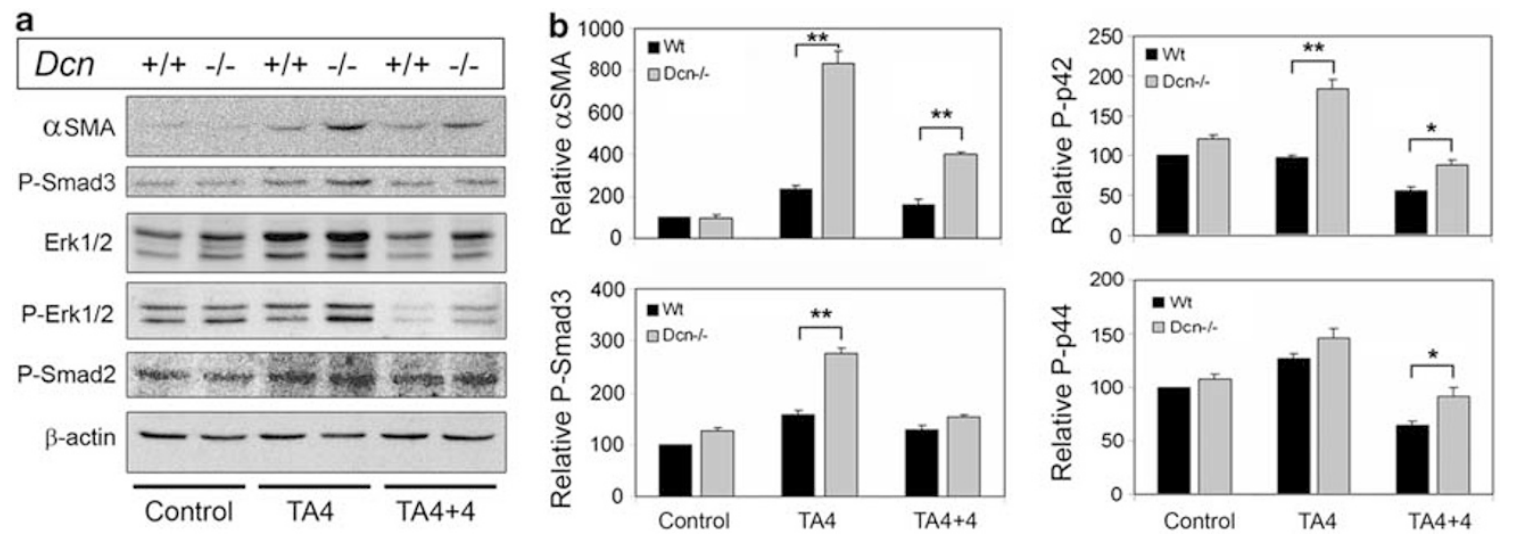

Figure 7 Amounts of Erk1/2, phospho-Erk1/2 (P-Erk1/2), phospho-Smad2 (P-Smad2), phospho-Smad3 (P-Smad3), and $\alpha$-smooth muscle actin ( $\alpha$ SMA) as detected by western immunoblotting (a). Pictures are representative of immunoblotting analyses of liver homogenates from two independent experiments run in triplicate. The genotype is indicated at the top and the various categories are listed at the bottom, including animals with no treatment (control), following a 4-month exposure to thioacetamide (TA4), and at the end of the regeneration period (TA4+4). $\beta$-Actin served as loading control.

(b) Densitometric quantification of immunoblottings for $\alpha$ SMA P-Smad3, P-p44, and P-p42. The values were normalized on $\beta$-actin levels. Data are expressed as mean \pm s.d. of duplicate experiments run in triplicate; ${ }^{* * P}<0.01 ;{ }^{*} P<0.05$. 

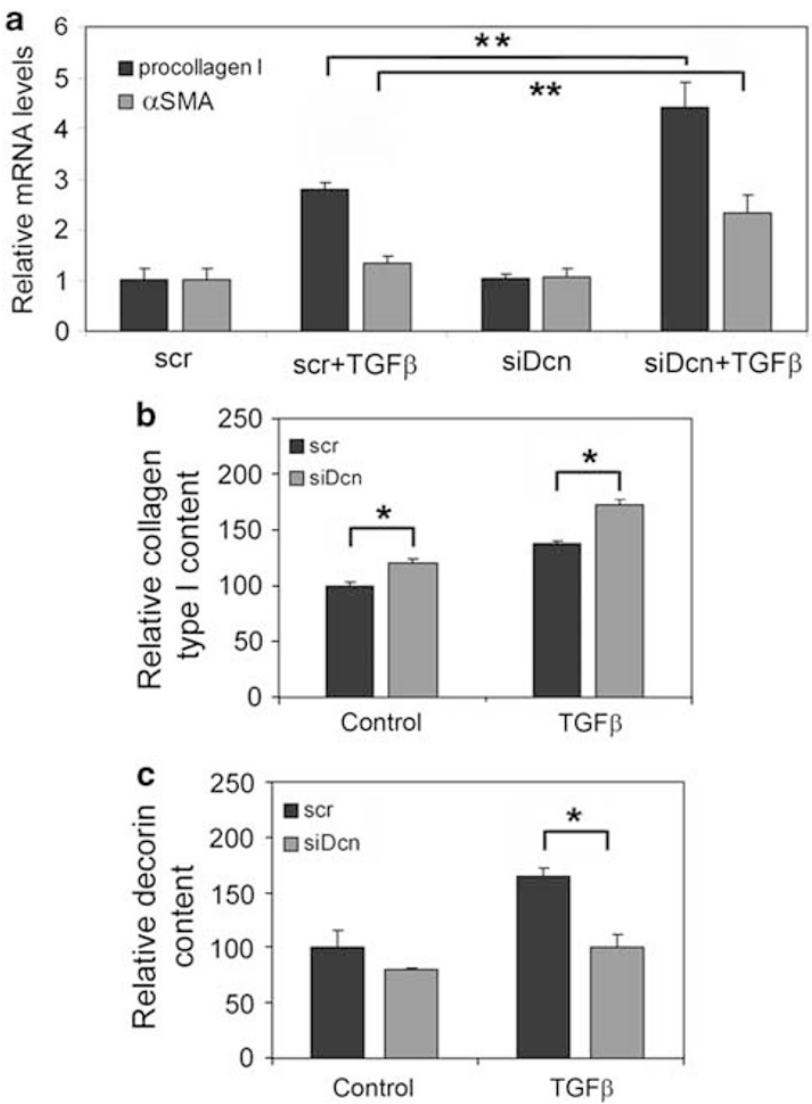

Figure 8 Analysis of LX2 cell activation by TGF $\beta$. (a) Quantitative RT-PCR analysis of procollagen type 1 , and $\alpha$-smooth muscle actin mRNA levels normalized on GAPDH. The data represent the mean \pm s.d. of duplicate experiments run in triplicates. (b) Determination of collagen 1 protein amount by dot blot in medium of LX2 cells with normal (scr) or silenced decorin content (siDcn) with or without TGF $\beta 1$ treatment. (c) Diagram of the relative decorin proteoglycan content from media of cells transfected with either scrambled or decorin-specific siRNAs. The data represent the mean \pm s.d. of duplicate experiments run in triplicates; ${ }^{*} P<0.05,{ }^{* *} P<0.01$.

At the protein level, decorin silencing caused an increase in collagen type 1 in the media of cells exposed to TGF $\beta 1$ $(P<0.05$; Figure $8 \mathrm{~b})$, and only a modest increase in siRNAtreated cells without exposure to the growth factor. In agreement with the in vivo data, TGF $\beta 1$ caused enhanced decorin production $(164 \%)$ in LX2 stellate cells $(P<0.05$; Figure 8c).

In full support of the results presented above, immunofluorescence staining for $\alpha$-smooth muscle actin of hepatic tissues from various animals showed increased immunopositive cells in the decorin-null livers, especially at 4 months (Figure 9a). Similarly, enhanced $\alpha$-smooth muscle actin immunostaining was observed when endogenous expression of decorin was decreased in LX2 hepatic stellate cells (Figure $9 \mathrm{~b}$ ), and these effects were more enhanced by TGF $\beta 1$ treatment. These findings support and corroborate the in vivo data that showed elevated amounts of $\alpha$-smooth muscle actin in $D c n-/-$ liver samples both at 4 months of TA treatment and after the recovery period (Figure 7a). The correlation between our in vivo and in vitro data was further corroborated by the fact that LX-2 hepatic stellate cells exhibited a significant increase in the $\alpha$-smooth muscle actin (Figure 10a and $\mathrm{b}$ ). In addition, TGF $\beta 1$-evoked induction of P-Smad3 was significantly enhanced in cells with reduced expression of endogenous decorin $(P<0.05$; Figure 10b, see also below).

Collectively, our findings indicated that endogenous hepatic decorin has a key role in the regulation of stellate cell activation insofar as genetic ablation of decorin or RNA interference strategies culminate in enhanced activation of stellate cells and a pronounced profibrotic phenotype.

\section{Knockdown of Endogenous Decorin Potentiates TGF $\beta 1$-Evoked Stimulation of Smad3 Phosphorylation in LX2 Stellate Cells}

To investigate the underlying mechanisms regulating the phosphorylation of Smad2 and Smad3 proteins, we performed immunoblotting of cells in which endogenous decorin was either left intact (scrambled siRNA) or reduced by addition of decorin gene-specific siRNA. We have shown above that the in vivo phosphorylated form of both proteins was elevated due to TA treatment but only P-Smad3 was significantly higher in $D c n-/-$ samples (Figure 7a). The results of our cell culture model system correlated well with those obtained with the animal experiments because after $48 \mathrm{~h}$ of TGF $\beta 1$ exposure the extent of increase in P-Smad2 was comparable in cells transfected with either scrambled or decorin-specific siRNAs (Figure 10b). In contrast, after TGF $\beta 1$ treatment, P-Smad3 levels were significantly higher in siDcn cells showing a 3.2- vs a 1.9-fold elevation in cells transfected with scrambled siRNA $(P<0.05$; Figure $10 \mathrm{~b})$.

Thus, decorin deficiency potentiates TGF $\beta 1 / \mathrm{Smad} 3$ axis suggesting that decorin in vivo might regulate the fine balance of connective tissue remodeling.

\section{DISCUSSION}

Several studies have shown that TGF $\beta 1$ is a profibrotic cytokine and it has a key role in development of diseases characterized by fibrotic remodeling, such as glomerulosclerosis, pulmonary, and hepatic fibrosis. ${ }^{17,42,43}$ As the original discovery that decorin binds to this growth factor, ${ }^{23}$ it has been shown that decorin/TGF $\beta 1$ interaction can block TGF $\beta 1$ bioactivity both in vitro and in vivo. ${ }^{24,44}$ These studies reported the efficacy of decorin in inhibiting not only fibroplasia, but also migration of fibroblasts, trophoblasts, and differentiation of myocytes. ${ }^{45,46}$ Previously, using a cohort of liver pathologies including chronic hepatitis, fibrosis, and cirrhosis, we found high amounts of TGF $\beta 1$ colocalized with decorin within the fibrotic areas of the liver. ${ }^{26}$ However, these findings could not distinguish between a decorin-mediated block of TGF $\beta 1$ activity and a bystander effect. Indeed, in contrast to dermal fibroblasts, ${ }^{47}$ TGF $\beta 1$ upregulates decorin production in hepatic stellate cells. ${ }^{48}$ Thus, enhanced deposition of decorin could reflect the stimulatory effect of 
a
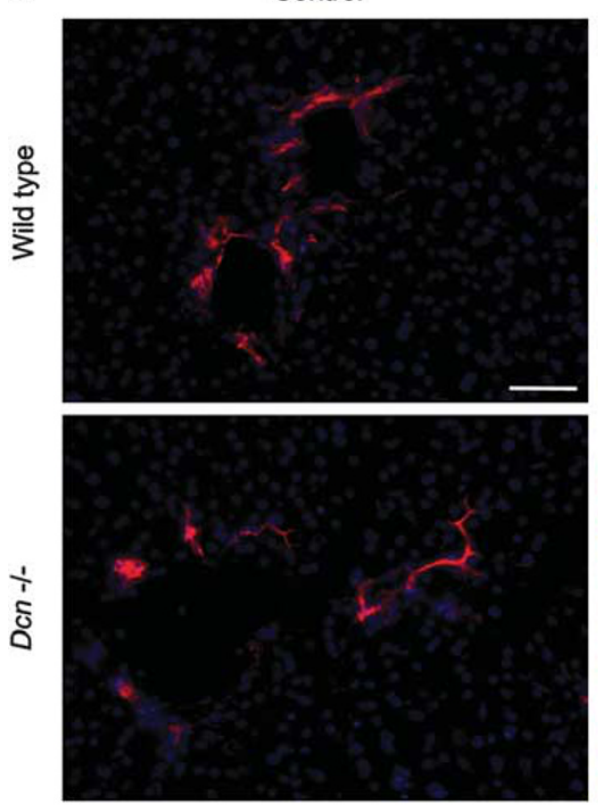

b

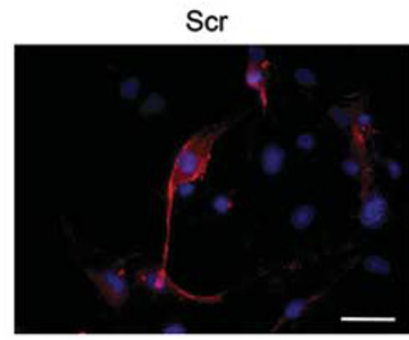

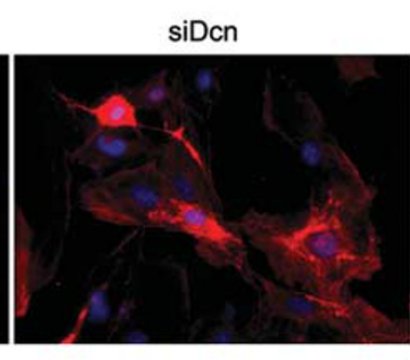

Control
TA4
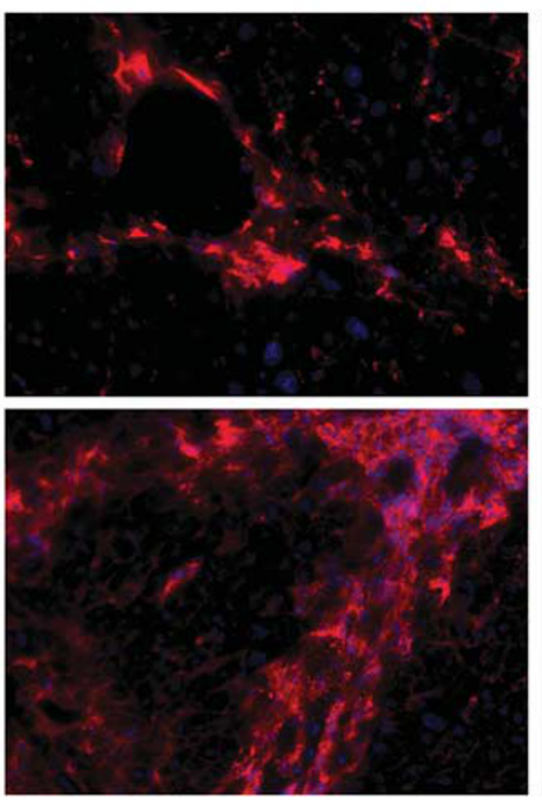

Scr

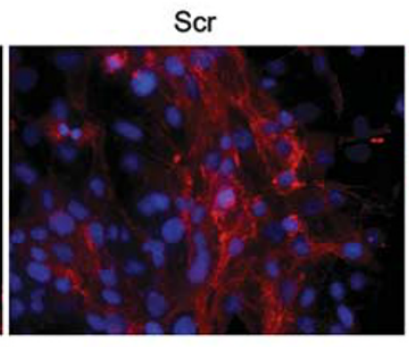

TA4+4
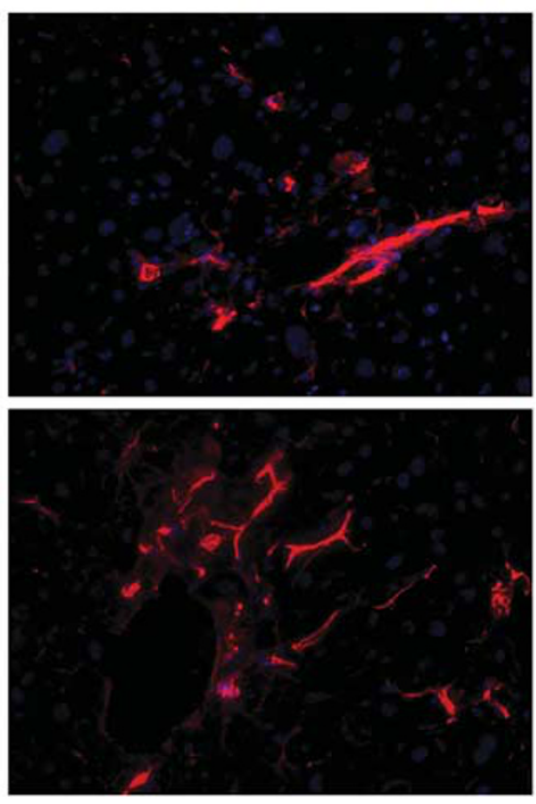

siDcn

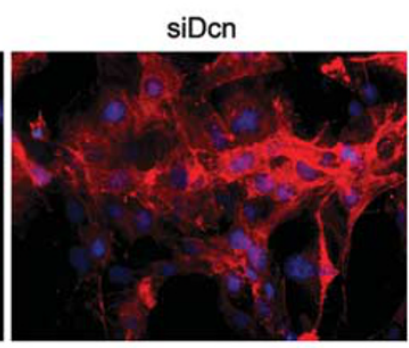

TGF $\beta$

Figure 9 Changes in $\alpha$-smooth muscle actin ( $\alpha$ SMA) in liver sections and in LX2 cells. (a) Immunostaining of $\alpha$ SMA on sections of wild-type (Wt) and decorin-null (Dcn-/-) livers after 4 months of TA exposure and at the end of the regression period (TA4 +4$)$. (b) Immuncytochemistry of $\alpha$ SMA performed on cells transfected with scrambled (scr) siRNA or with siRNA specific for decorin (siDcn) in the absence or presence of TGF $\beta 1 \mathrm{for} 48 \mathrm{~h}$. $\alpha$ SMA is shown as red and nuclei are counterstained with DAPI. Scale bar $=100 \mu \mathrm{m}$ for each picture.

overproduced TGF $\beta 1$, without necessarily implying a protective role of decorin against fibrosis. In the only in vitro liver fibrogenesis model, treatment of hepatic stellate cell cultures with the TGF $\beta 1$ resulted in enhanced production of extracellular matrix proteins and decorin could counteract this effect. ${ }^{49}$

In this investigation, we used a defined experimental animal model of liver fibrosis using mice with identical genetic background $(\mathrm{C} 57 \mathrm{Bl} / 6)$ except for the absence or presence of decorin. By comparing the fibrogenic response in wild-type and decorin-deficient livers, we provide strong genetic evidence for a role of decorin in protecting against fibrogenesis. By further following the animals for an additional 4 months of recovery period, during which time the animals were not subjected to TA in their diet, we answer an additional question as to whether decorin is also involved in the healing process.

Notably, without any experimental challenge, the amount of connective tissue in the livers from control and Dcn-/- animals did not differ from each other, in agreement with previous studies that have shown that decorin-null animals mature to adulthood without any major disease processes. ${ }^{29}$ However, soon after the start of TA exposure the regular dose given to wild-type mice had to be reduced by $50 \%$ as the compound proved to be toxic for the Dcn-/- animals. The degree of TA-induced matrix deposition was higher in the liver from decorin-null mice, and this was observed as early as the first month, lasting throughout the entire experimental period. This response correlated well with an enhancement of collagen I, III, and IV proteins in the decorin-deficient mice. However, during the same time interval, the steady-state mRNA levels for these three major collagens did not increase in parallel to the increased protein levels. These findings suggest that the clearance rather than the synthesis of collagens was impaired. This hypothesis was further corroborated by relative decrease in two major MMPs, MMP-2 and MMP-9, and by a concurrent increase in the hepatic levels of two major MMP inhibitors, namely 

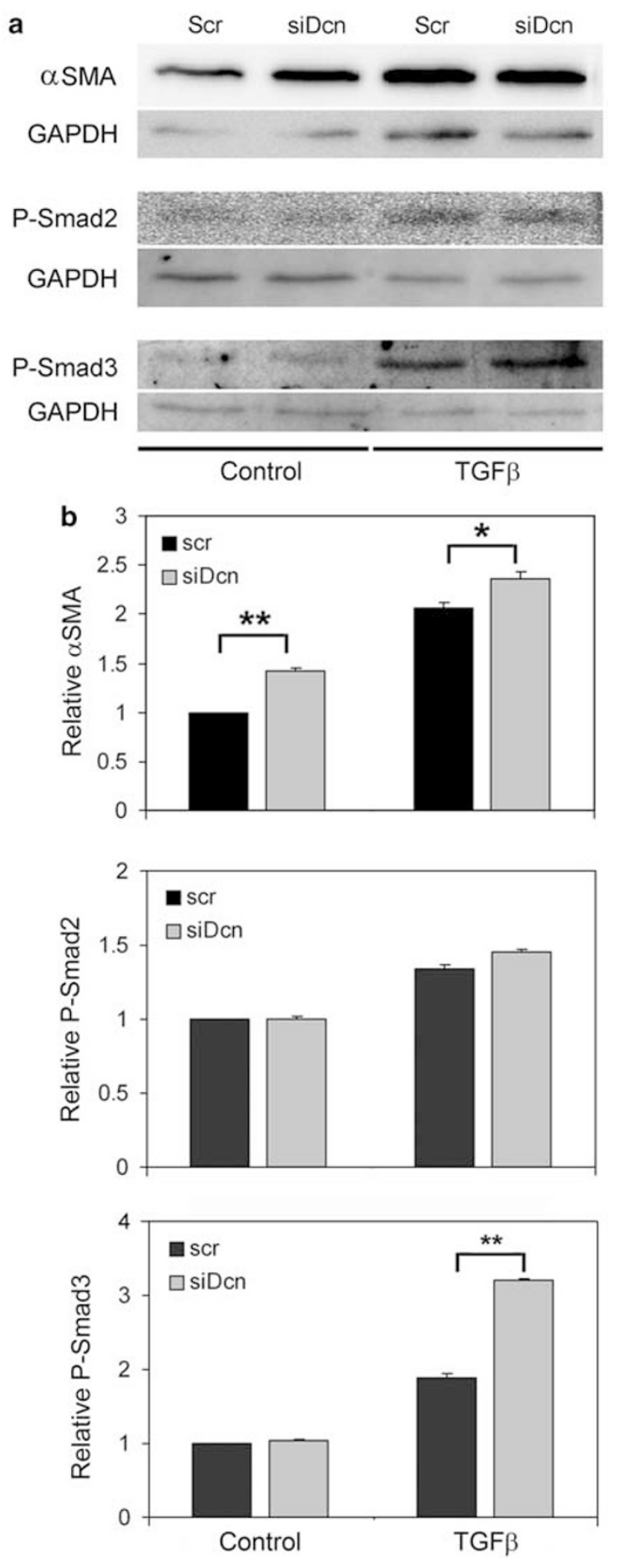

Figure 10 Western blot analysis of $\alpha$-smooth muscle actin ( $\alpha \mathrm{SMA})$, phospho-Smad2 (P-Smad2), and phospho-Smad3 (P-Smad3) in LX2 hepatic stellate cells (a). Pictures are representative of immunoblotting analyses of cell lysates from two independent experiments run in triplicate. (b) Quantification of $\alpha \mathrm{SMA}, \mathrm{P}-\mathrm{Smad} 2$, and P-Smad3 content normalized on GAPDH levels. ${ }^{*} P<0.05 ;{ }^{*} P<0.01$.

TIMP-1 and PAI-1. Nonetheless, other possible explanations need to be considered, ie, changes in transcription/translation efficiency or in mRNA and protein half-lives. Whether the changes observed in our model relate directly to lack of decorin or reflect enhanced TGF $\beta 1$ activity needs to be addressed in future studies. Indeed, an adenovirus-mediated direct effect of decorin on metalloproteases has been previously described, although the effect is cell dependent. ${ }^{50,51}$ On the other hand, TIMP-1 and PAI-1 levels can also be modulated by TGF $\beta 1 .{ }^{52,53}$

One of the most interesting findings of this study is the potential involvement of decorin not only in fibrogenesis, but also in the healing process, during which time numerous enzymes and cells, such as macrophages, would coordinate the clearance of the accumulated connective tissue. Wild-type animals completely recovered, with little or no residual fibrosis, within 4 months from the cessation of experimental liver injury. In contrast, not only the severity of the hepatic fibrosis was more marked in the decorin-null animals, but also the ability to clear their deposited connective tissue. At the end of the experimental period, the decorin-null livers showed elevated collagens I, III and IV, as well as elevated TIMP-1 and PAI-1 mRNA steady-state levels. Moreover, the $D c n-/-$ livers showed significantly higher collagen I protein level, whereas the MMP activities were comparable to the wild-type livers. Thus, we conclude that decorin is a central player not only in the initial matrix deposition after hepatic injury, but also during the subsequent phases of healing and remodeling. This is in agreement with studies indicating that decorin has a key role during the healing of myocardial infarction, ${ }^{54}$ during cutaneous wound healing, ${ }^{55}$ and in various animal models of renal fibrosis and injury. $35,56,57$

To reveal the underlying mechanism of the cellular processes, we measured the state of Erk1/2 activation and $\mathrm{P}-\mathrm{Smad} 2 / 3$ proteins, all known downstream effectors of the TGF $\beta 1$ signaling pathway. Phosphorylation of Smad2/3 proteins in fibrotic diseases has been described many times previously. ${ }^{58-61}$ In this study, we did not detect any significant difference in P-Smad2 between wild-type and decorin-deficient animals. However, significant difference was detected in the activation of Smad3 both in Dcn-/- livers after 4 months of TA exposure as well as in decorin-deficient LX2 human stellate cells after TGF $\beta 1$ exposure, suggesting that the signaling pathway causing the increase in matrix production in Dcn-/- animals might be related to the Smad pathway. The prominent role of $\operatorname{Smad} 3$ is well documented as targeted disruption of Smad3 confers resistance to the development of dimethylnitrosamine-induced hepatic fibrosis in mice. ${ }^{62}$ Moreover, it is well documented that maximal expression of collagen type I in activated hepatic stellate cells, ie, the most fibrogenic cell type in liver, requires Smad3 rather than Smad2, both in vivo and in cultured cells. ${ }^{63}$

Activation of the Erk1/2 was also remarkably higher in Dcn-/- mice both during the fibrotic and regenerative periods. Indeed, several studies have reported the importance of non-Smad pathways of TGF $\beta$ signaling, ${ }^{60,64,65}$ which culminates in elevated collagen production, in transdifferentiation of hepatic stellate cells into myofibroblasts, ${ }^{64}$ and in 
epithelial-to-mesenchymal transition. ${ }^{65}$ We do not know whether activation of Erk $1 / 2$ occurs through the TGF $\beta$ receptor or through cross talk with different receptor tyrosine kinases. Notably, Erk1/2 is downstream of both EGFR and Met, and decorin is a known negative regulator of both these receptors. Thus, the lack of decorin might cause a protracted activation of one or both of these receptors, especially the Met receptor that is highly expressed in hepatocytes.

In conclusion, although we do not know whether collagenbound decorin is as effective as soluble decorin, our studies provide the first evidence that decorin, and perhaps other SLRP members, might have a direct role in liver fibrogenesis and healing. It is conceivable that not the absolute amount of decorin, but the ratio of decorin to active TGF $\beta 1$ might be important in combating hepatic fibrosis.

Supplementary Information accompanies the paper on the Laboratory Investigation website (http://www.laboratoryinvestigation.org)

\section{ACKNOWLEDGEMENTS}

We thank Dr Scott Friedman (Mount Sinai School of Medicine, NY) for providing the LX2 stellate cells. This work was supported in part by Hungarian Scientific Research Fund, Grants 67925, 042672, 75468, and by the National Institutes of Health grant RO1 CA39481 (to RVI).

\section{DISCLOSURE/CONFLICT OF INTEREST}

The authors declare no conflict of interest.

1. Hope TA, Herfkens RJ, Denianke KS, et al. Nephrogenic systemic fibrosis in patients with chronic kidney disease who received gadopentetate dimeglumine. Invest Radiol 2009;44:135-139.

2. Zois $C D$, Baltayiannis $G H$, Karayiannis $P$, et al. Systematic review: hepatic fibrosis-regression with therapy. Aliment Pharmacol Ther 2008;28:1175-1187.

3. Calvaruso V, Maimone $S$, Gatt $A$, et al. Coagulation and fibrosis in chronic liver disease. Gut 2008;57:1722-1727.

4. Schnaper HW. Balance between matrix synthesis and degradation: a determinant of glomerulosclerosis. Pediatr Nephrol 1995;9:104-111.

5. Balsano C, Alisi A, Nobili V. Liver fibrosis and therapeutic strategies: the goal for improving metabolism. Curr Drug Targets 2009;10:505-512.

6. Epple $A$, Kuhn HA, Leveringhaus $M$, et al. Etiology, complications and prognosis of liver cirrhosis in 917 patients. II. Causes of death and prognosis in liver cirrhosis. Lebensversicher Med 1979;31:117-122.

7. Fartoux L, Serfaty L. Liver cirrhosis in adults: etiology and specific treatments. Rev Prat 2005;55:1539-1548.

8. Friedman SL. Liver fibrosis-from bench to bedside. J Hepatol 2003;38(Suppl 1):S38-S53.

9. Kato I, Tominaga S, Ikari A. The risk and predictive factors for developing liver cancer among patients with decompensated liver cirrhosis. Jpn J Clin Oncol 1992;22:278-285.

10. La Vecchia C, Negri E, Cavalieri d'Oro L, et al. Liver cirrhosis and the risk of primary liver cancer. Eur J Cancer Prev 1998;7:315-320.

11. Albillos Martinez A. What is the treatment of choice in a patient with liver cirrhosis and esophageal varices that have bled to prevent rebleeding: beta-blockers, endoscopic ligation or both?. Gastroenterol Hepatol 2009;32:124-125.

12. Garcia-Tsao G, Lim J. Management and treatment of patients with cirrhosis and portal hypertension: recommendations from the Department of Veterans Affairs Hepatitis C Resource Center Program and the National Hepatitis C Program. Am J Gastroenterol 2009;104:1802-1829.

13. Vallet-Pichard A, Mallet V, Costentin CE, et al. Treatment of HBV-related cirrhosis. Expert Rev Anti Infect Ther 2009;7:527-535.

14. Schmidt A, Lorkowski S, Seidler D, et al. TGF-beta1 generates a specific multicomponent extracellular matrix in human coronary SMC. Eur J Clin Invest 2006;36:473-482.
15. De Bleser PJ, Niki T, Rogiers V, et al. Transforming growth factor-beta gene expression in normal and fibrotic rat liver. J Hepatol 1997;26: 886-893.

16. Gauldie J, Bonniaud P, Sime P, et al. TGF-beta, Smad3 and the process of progressive fibrosis. Biochem Soc Trans 2007;35:661-664.

17. Kanzler S, Lohse AW, Keil A, et al. TGF-beta1 in liver fibrosis: an inducible transgenic mouse model to study liver fibrogenesis. Am J Physiol 1999;276:G1059-G1068.

18. Wang $\mathrm{H}$, Mengsteab $\mathrm{S}$, Tag CG, et al. Transforming growth factor-beta1 gene polymorphisms are associated with progression of liver fibrosis in Caucasians with chronic hepatitis C infection. World J Gastroenterol 2005;11:1929-1936.

19. Shek FW, Benyon RC. How can transforming growth factor beta be targeted usefully to combat liver fibrosis? Eur J Gastroenterol Hepatol 2004; $16: 123-126$.

20. lozzo RV. The biology of the small leucine-rich proteoglycans Functional network of interactive proteins. J Biol Chem 1999;274: 18843-18846.

21. Schaefer L, lozzo RV. Biological functions of the small leucine-rich proteoglycans: from genetics to signal transduction. J Biol Chem 2008;283:21305-21309.

22. Ameye L, Young MF. Mice deficient in small leucine-rich proteoglycans: novel in vivo models for osteoporosis, osteoarthritis, Ehlers-Danlos syndrome, muscular dystrophy, and corneal diseases. Glycobiology 2002;12:107R-116R

23. Yamaguchi Y, Mann DM, Ruoslahti E. Negative regulation of transforming growth factor-beta by the proteoglycan decorin. Nature 1990; 346:281-284.

24. Zhang Z, Li XJ, Liu Y, et al. Recombinant human decorin inhibits cell proliferation and downregulates TGF-beta1 production in hypertrophic scar fibroblasts. Burns 2007;33:634-641.

25. Isaka Y, Brees DK, Ikegaya K, et al. Gene therapy by skeletal muscle expression of decorin prevents fibrotic disease in rat kidney. Nat Med 1996;2:418-423.

26. Dudas J, Kovalszky I, Gallai M, et al. Expression of decorin, transforming growth factor-beta 1, tissue inhibitor metalloproteinase 1 and 2, and type IV collagenases in chronic hepatitis. Am J Clin Pathol 2001;115:725-735.

27. Weber IT, Harrison RW, lozzo RV. Model structure of decorin and implications for collagen fibrillogenesis. J Biol Chem 1996;271: 31767-31770.

28. Zhang G, Ezura Y, Chervoneva I, et al. Decorin regulates assembly of collagen fibrils and acquisition of biomechanical properties during tendon development. J Cell Biochem 2006;98:1436-1449.

29. Danielson KG, Baribault H, Holmes DF, et al. Targeted disruption of decorin leads to abnormal collagen fibril morphology and skin fragility. J Cell Biol 1997;136:729-743.

30. Santra M, Reed CC, lozzo RV. Decorin binds to a narrow region of the epidermal growth factor (EGF) receptor, partially overlapping but distinct from the EGF-binding epitope. J Biol Chem 2002;277 :35671-35681.

31. Reed CC, Gauldie J, lozzo RV. Suppression of tumorigenicity by adenovirus-mediated gene transfer of decorin. Oncogene 2002;21: 3688-3695.

32. Csordas G, Santra M, Reed CC, et al. Sustained down-regulation of the epidermal growth factor receptor by decorin. A mechanism for controlling tumor growth in vivo. J Biol Chem 2000;275:32879-32887.

33. Fiedler LR, Schonherr $E$, Waddington $R$, et al. Decorin regulates endothelial cell motility on collagen I through activation of insulin-like growth factor I receptor and modulation of alpha2beta1 integrin activity. J Biol Chem 2008;283:17406-17415.

34. Goldoni S, Humphries A, Nystrom A, et al. Decorin is a novel antagonistic ligand of the Met receptor. J Cell Biol 2009;185: 743-754.

35. Schaefer L, Tsalastra W, Babelova A, et al. Decorin-mediated regulation of fibrillin-1 in the kidney involves the insulin-like growth factor-I receptor and mammalian target of rapamycin. Am J Pathol 2007;170:301-315.

36. Schönherr E, Sunderkotter C, lozzo RV, et al. Decorin, a novel player in the insulin-like growth factor system. J Biol Chem 2005;280: 15767-15772.

37. Merline R, Lazaroski S, Babelova A, et al. Decorin deficiency in diabetic mice: aggravation of nephropathy due to overexpression of profibrotic 
factors, enhanced apoptosis and mononuclear cell infiltration. J Physiol Pharmacol 2009;60(Suppl 4):5-13.

38. Xu L, Hui AY, Albanis E, et al. Human hepatic stellate cell lines, LX-1 and LX-2: new tools for analysis of hepatic fibrosis. Gut 2005;54:142-151.

39. Bradford MM. A rapid and sensitive method for the quantitation of microgram quantities of protein utilizing the principle of protein-dye binding. Anal Biochem 1976;72:248-254.

40. Woessner Jr JF. The determination of hydroxyproline in tissue and protein samples containing small proportions of this imino acid. Arch Biochem Biophys 1961;93:440-447.

41. Fels IG. Determination of hydroxyproline in liver. Clin Chem 1958;4:62-65.

42. Clouthier DE, Comerford SA, Hammer RE. Hepatic fibrosis, glomerulosclerosis, and a lipodystrophy-like syndrome in PEPCK-TGFbeta1 transgenic mice. J Clin Invest 1997;100:2697-2713.

43. El-Gamel A, Awad MR, Hasleton PS, et al. Transforming growth factorbeta (TGF-beta1) genotype and lung allograft fibrosis. J Heart Lung Transplant 1999;18:517-523.

44. Huijun W, Long C, Zhigang Z, et al. Ex vivo transfer of the decorin gene into rat glomerulus via a mesangial cell vector suppressed extracellular matrix accumulation in experimental glomerulonephritis. Exp Mol Pathol 2005;78:17-24.

45. Droguett $R$, Cabello-Verrugio $C$, Riquelme $C$, et al. Extracellular proteoglycans modify TGF-beta bio-availability attenuating its signaling during skeletal muscle differentiation. Matrix Biol 2006;25 332-341.

46. Fischer JW, Kinsella MG, Levkau B, et al. Retroviral overexpression of decorin differentially affects the response of arterial smooth muscle cells to growth factors. Arterioscler Thromb Vasc Biol 2001;21:777-784.

47. Kahari VM, Larjava $\mathrm{H}$, Uitto J. Differential regulation of extracellular matrix proteoglycan (PG) gene expression. Transforming growth factor-beta 1 up-regulates biglycan (PGl), and versican (large fibroblast PG) but down-regulates decorin (PGII) mRNA levels in human fibroblasts in culture. J Biol Chem 1991;266:10608-10615.

48. Breitkopf K, Haas S, Wiercinska E, et al. Anti-TGF-beta strategies for the treatment of chronic liver disease. Alcohol Clin Exp Res 2005;29: 121S-131S.

49. Shi YF, Zhang Q, Cheung PY, et al. Effects of rhDecorin on TGF-beta1 induced human hepatic stellate cells LX-2 activation. Biochim Biophys Acta 2006;1760:1587-1595.

50. Dong FQ, Li H, Wu F, et al. [Effects of overexpression of decorin on matrix metalloproteinases 2 and 9 in rat mesangial and tubular cells]. Zhonghua Yi Xue Za Zhi 2008;88:3444-3447.
51. Al Haj Zen A, Lafont A, Durand E, et al. Effect of adenovirus-mediated overexpression of decorin on metalloproteinases, tissue inhibitors of metalloproteinases and cytokines secretion by human gingival fibroblasts. Matrix Biol 2003;22:251-258.

52. Akool el $\mathrm{S}$, Doller A, Muller R, et al. Nitric oxide induces TIMP-1 expression by activating the transforming growth factor beta-Smad signaling pathway. J Biol Chem 2005;280:39403-39416.

53. Kutz SM, Hordines J, McKeown-Longo PJ, et al. TGF-beta1-induced PAI1 gene expression requires MEK activity and cell-to-substrate adhesion. J Cell Sci 2001:114:3905-3914.

54. Weis SM, Zimmerman SD, Shah $M$, et al. A role for decorin in the remodeling of myocardial infarction. Matrix Biol 2005;24:313-324.

55. Jarvelainen $\mathrm{H}$, Puolakkainen $\mathrm{P}$, Pakkanen $\mathrm{S}$, et al. A role for decorin in cutaneous wound healing and angiogenesis. Wound Repair Regen 2006;14:443-452.

56. Schaefer L, Macakova K, Raslik I, et al. Absence of decorin adversely influences tubulointerstitial fibrosis of the obstructed kidney by enhanced apoptosis and increased inflammatory reaction. Am J Pathol 2002;160:1181-1191.

57. Williams KJ, Qiu G, Usui HK, et al. Decorin deficiency enhances progressive nephropathy in diabetic mice. Am J Pathol 2007;171: 1441-1450.

58. Border WA, Noble NA. Transforming growth factor beta in tissue fibrosis. N Engl J Med 1994;331:1286-1292.

59. Flanders KC. Smad3 as a mediator of the fibrotic response. Int J Exp Pathol 2004;85:47-64.

60. Massague J. TGF-beta signal transduction. Annu Rev Biochem 1998;67:753-791

61. Miyazono K, ten Dijke P, Heldin CH. TGF-beta signaling by Smad proteins. Adv Immunol 2000;75:115-157.

62. Latella G, Vetuschi A, Sferra R, et al. Targeted disruption of Smad3 confers resistance to the development of dimethylnitrosamineinduced hepatic fibrosis in mice. Liver Int 2009:29:997-1009.

63. Schnabl B, Kweon YO, Frederick JP, et al. The role of Smad3 in mediating mouse hepatic stellate cell activation. Hepatology 2001;34:89-100.

64. Pannu J, Nakerakanti S, Smith E, et al. Transforming growth factor-beta receptor type I-dependent fibrogenic gene program is mediated via activation of Smad1 and ERK1/2 pathways. J Biol Chem 2007;282: 10405-10413.

65. Zhang YE. Non-Smad pathways in TGF-beta signaling. Cell Res 2009; 19:128-139. 